\title{
An Observational Study of Bovine Pericardial Patch Angioplasty as a surgical option for Infected Aortic Aneurysms
}

Hideyuki Harada ${ }^{1 *}$, Xiaoning Tong ${ }^{1 a}$, Masahiko Narita ${ }^{1 b}$, Ryo Ohkubo ${ }^{1 \mathrm{c}}$, Fumiaki Kimura ${ }^{1 \mathrm{~d}}$ and Toshio Baba ${ }^{1 \mathrm{e}}$ ${ }^{1}$ Department of Cardiovascular Surgery, Kushiro Kojinkai Memorial Hospital, Japan

*Corresponding Author: Hideyuki Harada, Department of Cardiovascular Surgery, Kushiro Kojinkai Memorial Hospital, Japan.

Received date: February 08, 2021: Accepted date: February 19, 2021: Published date: April 05, 2021

Citation: Harada H, Tong X, Narita M, Ohkubo R, Kimura F and Baba T, (2021) An Observational Study of Bovine Pericardial Patch Angioplasty as a surgical option for Infected Aortic Aneurysms J. of Clin Case Rep and Stu 2(2); DOI: 10.31579/2690-8808/064

Copyright: (C) 2021: Hideyuki Harada. This is an open access article distributed under the Creative Commons Attribution License, which permits unrestricted use, distribution, and reproduction in any medium, provided the original work is properly cited.

\begin{abstract}
Background: An infected aortic aneurysm (IAA) is a rare and life-threatening disease. The aim of this study is to elucidate mid-term outcomes of IAA, incorporating patch angioplasty with bovine pericardium.

Materials and Methods: Between June 2011 and August 2020, eight patients (one woman, seven men) with infected aneurysms of the thoracic and abdominal aorta were treated surgically.

Results: There was no surgical/hospital death. There were two late deaths at follow-up. One patient (patient 6) was re-admitted to the hospital with vomiting blood four months after surgery and died despite treatment. Another patient (patient 5) died at his home 12 months after surgery, and the cause of death was unknown. Six patients remained alive with no evidence of recurrent aneurysm formation due to infection at a mean follow-up of 70.3 (range, 13-110) months.

Conclusions: BPPA could be one of the surgical options for IAA, especially in patients with severe adhesion around the aneurysm.

Key words: infected aortic aneurysm; juxtarenal aortic aneurysm; bovine pericardial patch angioplasty
\end{abstract}

\section{Introduction}

An infected aortic aneurysm (IAA) is a rare and life-threatening disease $[1,2]$. Surgical treatment for IAA is difficult and the ideal surgical procedure and optimal graft material remain subjects of debate [3]. Bovine pericardial patches (BPPs) are used in the infected fields $[4,5,6]$. In view of the anatomic characteristic of saccular form in IAAs, we completed a patch repair of the aortic intima defect using a BPP. Bovine pericardial patch angioplasty (BPPA) has low invasiveness because it minimizes the dissection range around the aneurysm, and handling of bovine pericardium is easy, which may shorten the operative time, hence potentially beneficial in clinical outcome $[3,7,8]$. The aim of this study is to elucidate mid-term outcomes of IAA, incorporating patch angioplasty with bovine pericardium.

\section{Materials and Methods}

Between June 2011 and August 2020, eight patients (one woman, seven men) were diagnosed with infected aneurysms of the thoracic and abdominal aorta. Age at operation range from 60 to 86, average 75 years. Patients with an infected aneurysm after previous vascular surgery, or a prosthetic graft infection, or those with aortoduodenal fistulas without previously infected aneurysm, were excluded from the study (Table 1). 


\begin{tabular}{|c|c|c|c|c|c|c|c|c|c|c|c|c|c|}
\hline $\begin{array}{l}\text { Patient } \\
\text { No. }\end{array}$ & Sex & $\begin{array}{c}\text { Age } \\
\text { (vear } \\
\text { s) }\end{array}$ & Symptoms & Location & $\begin{array}{l}\text { Direction } \\
\text { of Protruded } \\
\text { Aneurysm }\end{array}$ & Rupture & Procedure & $\begin{array}{l}\text { Additional } \\
\text { operation }\end{array}$ & $\begin{array}{l}\text { Blood } \\
\text { culture }\end{array}$ & Organism & $\begin{array}{l}\text { In-hospital } \\
\text { death }\end{array}$ & $\begin{array}{l}\text { Follow up } \\
\text { (months) }\end{array}$ & Results \\
\hline 1 & F & 86 & $\begin{array}{l}\text { Fever } \\
\text { Back pain } \\
\text { Abdominal pain }\end{array}$ & Juxtarenal & Posterior & $(+)$ & BPPA & Omentopexy & $(-)$ & Unknown & No & 110 & Alive \\
\hline 2 & M & 76 & $\begin{array}{l}\text { Shight fever } \\
\text { Back pain } \\
\text { Abdominal pain }\end{array}$ & Juxtarenal & Posterior & $(-)$ & BPPA & Omentopexy & $(-)$ & Unknown & No & 86 & Alive \\
\hline 3 & M & 60 & $\begin{array}{l}\text { Fever } \\
\text { Back pain } \\
\text { Abdomanal pain }\end{array}$ & Infrarenal & Anterior & $(-)$ & BPPA & Omentopexy & $(-)$ & Uniknown & No & 84 & Alve \\
\hline 4 & M & 83 & $\begin{array}{l}\text { Stight fever } \\
\text { Abdominal pain }\end{array}$ & $\begin{array}{l}\text { Thoracoabdomi } \\
\text { nal }\end{array}$ & Anterior & $(-)$ & BPPA & & $(-)$ & Unknown & No & 81 & Alive \\
\hline 5 & M & 79 & $\begin{array}{l}\text { Slight fever } \\
\text { Left abdominal } \\
\text { pain } \\
\text { Lumbago } \\
\text { Melena }\end{array}$ & Infrarenal & Right anterior & $(+)$ & BPPA & Omentopexy & $(+)$ & $\begin{array}{l}\text { Staphyloe } \\
\text { occus } \\
\text { auveris. }\end{array}$ & No & 12 & Died \\
\hline 6 & M & 74 & $\begin{array}{l}\text { Bloody stool } \\
\text { Melena }\end{array}$ & Infrarenal & Left anterior & $(+)$ & BPpA & $\begin{array}{l}\text { Omentopexy } \\
\text {,colostomy }\end{array}$ & $\theta$ & $\begin{array}{l}\text { Sorvptococ } \\
\text { cus }\end{array}$ & No & 4 & Died \\
\hline 7 & M & 66 & $\begin{array}{l}\text { Slight fever } \\
\text { Left abdominal } \\
\text { pain } \\
\text { Appetite loss }\end{array}$ & Infrarenal & Left anterior & $(+)$ & In-situ graft & Omentopexy & $(-)$ & Unknown & No & 61 & Alive \\
\hline 8 & M & 76 & $\begin{array}{l}\text { Fever } \\
\text { Abdominal pain }\end{array}$ & $\begin{array}{l}\text { Thoracoabdorni } \\
\text { nal }\end{array}$ & Right lateral & $(-)$ & BPPA & & $\leftrightarrow$ & Unknown & No & 13 & Alive \\
\hline
\end{tabular}

BPPA = bovine pericardial patch angioplasty.

Table 1. Patient profiles

The diagnosis of IAA was confirmed based on a combination of clinical symptoms and signs of infection, results of laboratory tests (white blood cell count and C-reactive protein levels), and typical imaging study findings (saccular aneurysm, para-aortic soft tissue infiltration, and abnormal fluid accumulation around the aneurysm; Figure 1) [9].
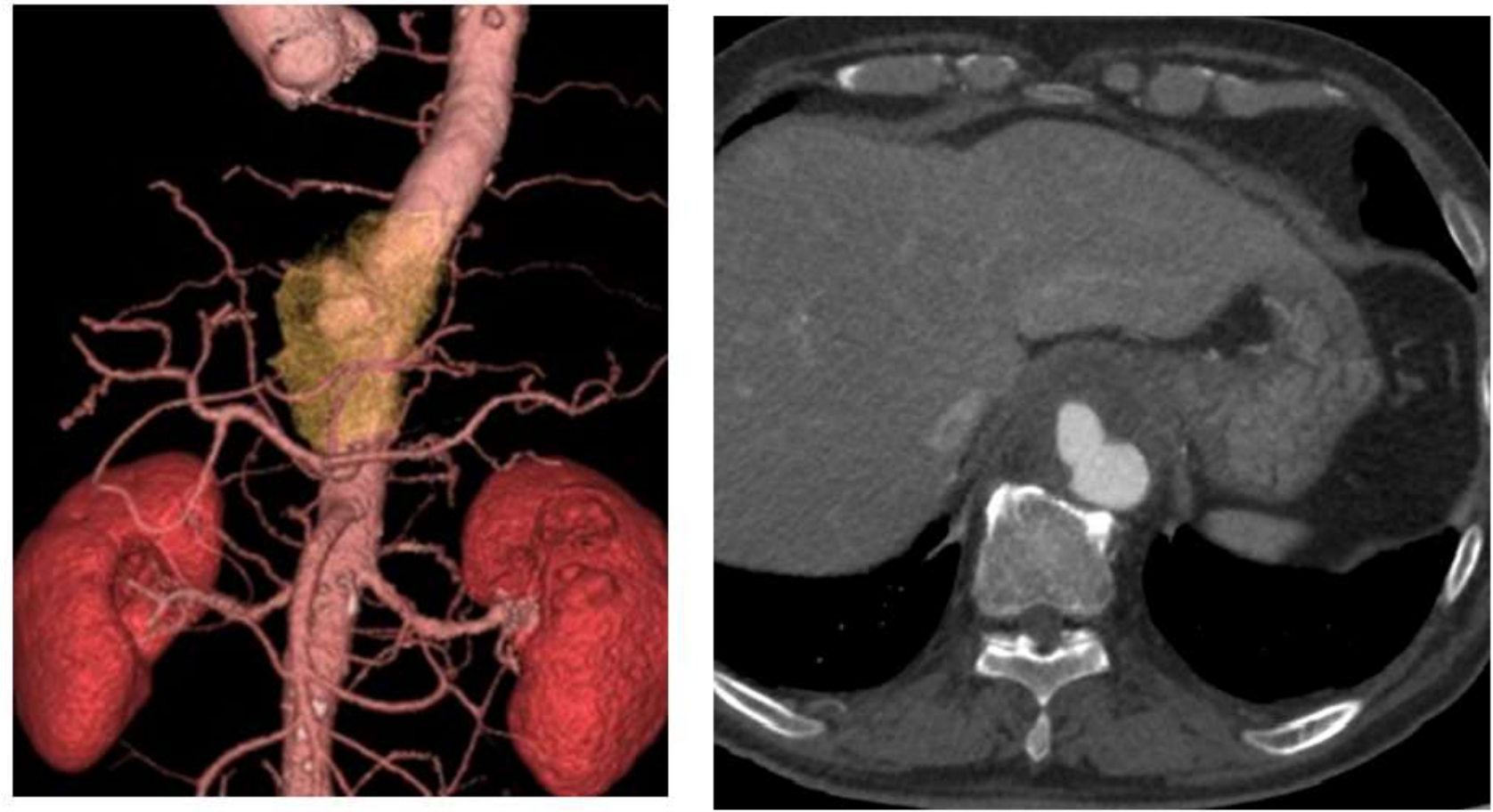

Figure 1. An immediate CT angiography showed a saccular formed aneurysm and adjacent opacified extra-aortic space (arrow) located at the antero-lateral wall of the thoracoabdominal aorta above the celiac axis (patient 8).

In some cases, 18F-fluorodeoxyglucose (FDG)- positron emission tomography (PET)/CT was used to confirm the diagnosis (Figure 2). 


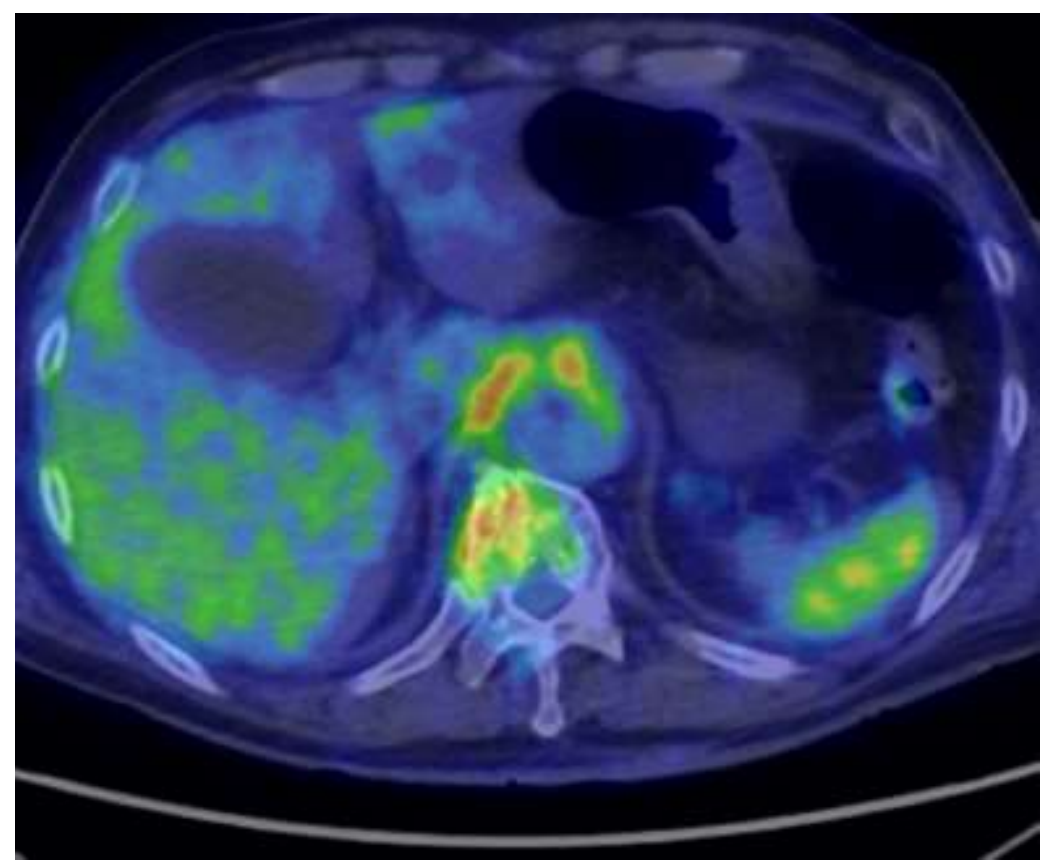

Figure 2. PETCT showed a high concentration of FDG in the aortic aneurysm (patient 8).

Once the diagnosis of primary IAA was established, intravenous broadspectrum antibiotics were administrated empirically. A most appropriate antibiotic was determined after culture results and sensitivity reports were available. All patients received intravenous antibiotic treatment for at least 4 weeks or until their body temperature, white blood cell count, and C-reactive protein levels turn to normal. After discharge, oral antibiotic treatment was continued for at least 6 to 11 months

Of the eight patients, the infrarenal abdominal aorta was involved in four patients, and the thoracoabdominal aorta, and juxtarenal aorta in two each. A rupture was found in four of the 8 patients, including an aortic sigmoid colon fistula in one. Six patients were performed through midline abdominal approach and two patients through thoracoabdominal approach. Severe adhesion around the aneurysm was observed in all cases. Partial cardiopulmonary bypass and selective visceral artery perfusion was used in two patients with infected thoracoabdominal aortic aneurysm (Figure 3).

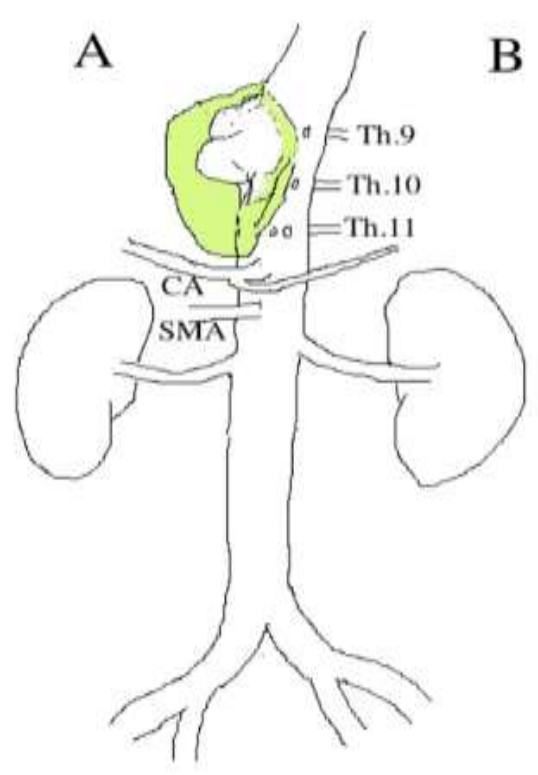

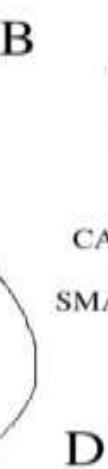

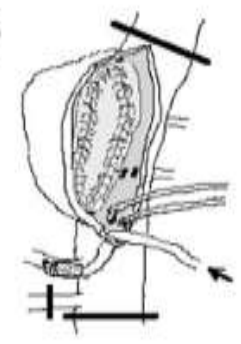

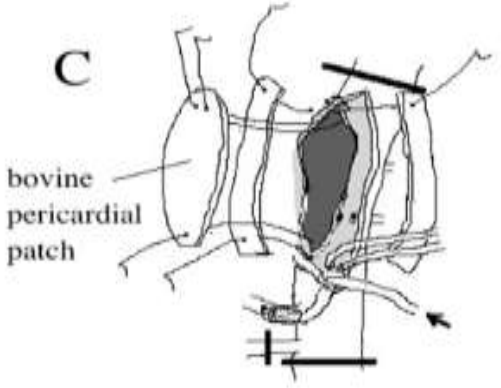

$\mathrm{E}$

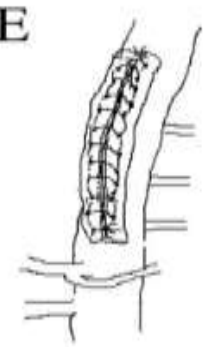

Figure 3. Schematic drawing of the operative findings (patient 8). A: The aneurysm of the thoracoabdominal aorta was markedly expanded. Severe adhesion around the aneurysm was observed. B: Distal descending thoracic aorta (Th 8 ) and the aorta just above the left renal artery between the Th12 and L1 were cross-clamped. Superior mesenteric artery (SMA) was clamped. A vertical aortotomy was made. The defect of intima (5x2.5cm) was found at the anterior of the aorta. Celiac artery (CA) was cannulated and perfused by cardiopulmonary bypass blood. C, D: The bovine pericardial patch $(7 \times 3 \mathrm{~cm})$ angioplasty was performed with 3-0 Prolene continuous sutures using bovine pericardial strips with preserving intercostal arteries $($ Th10, 11, 12). E: The aortotomy was closed using bovine pericardial strips. 
Continuous cold perfusion of the kidneys was used in two patients (patients 1 and 2) with infected juxtarenal aortic aneurysm (Figure 4).

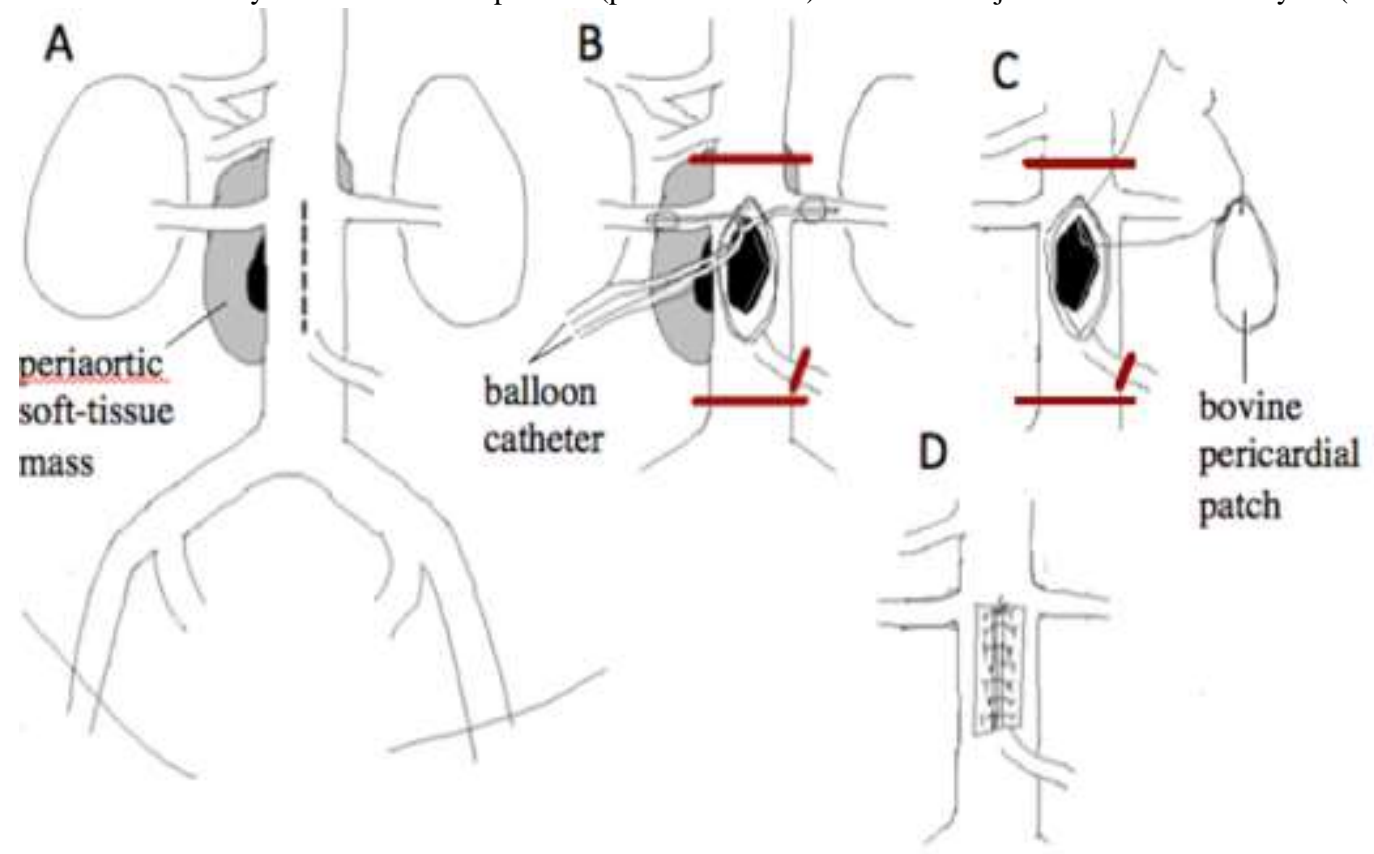

Figure 4. Schematic drawing of the operative findings (patient 1). A: A longitudinal aortotomy was performed at the anterior wall of the inter-renal aorta to expose the aortic defect at the posterior wall of the aorta. B: Insertion of the balloon-tipped irrigation catheters from the opened juxtarenal aorta in the renal orifices to provide renal hypothermia with cold saline solution. $\mathbf{C}$ : After copious irrigation of the aneurysmal sac, the aortic defect at the posterior wall was closed with the bovine pericardial patch. D: The aortotomy was closed using bovine pericardial strips.

Mural thrombus was removed after aneurysm was incised, and then irrigated with saline solution. BPPs were used to close the defects with double 3-0 Prolene continuous sutures using bovine pericardial strips in
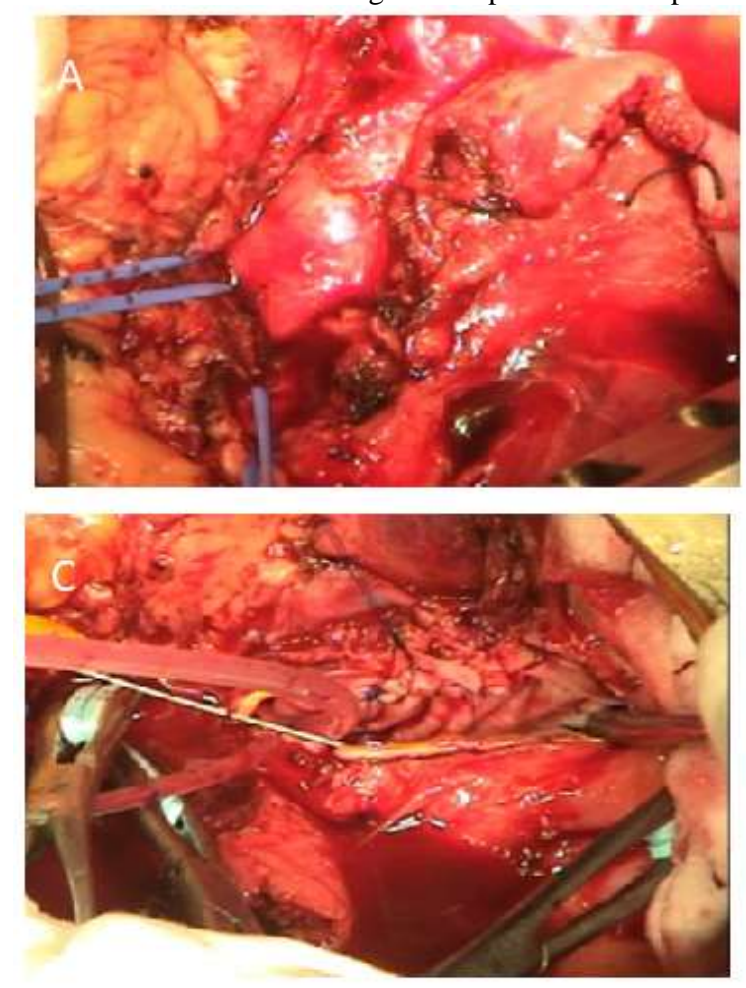

seven patients. However, the arterial wall in 1 (patient 7) was too fragile to repair, resection of aneurysm and replacement with rifampicin-soaked Dacron graft was required (Figure 6,7).
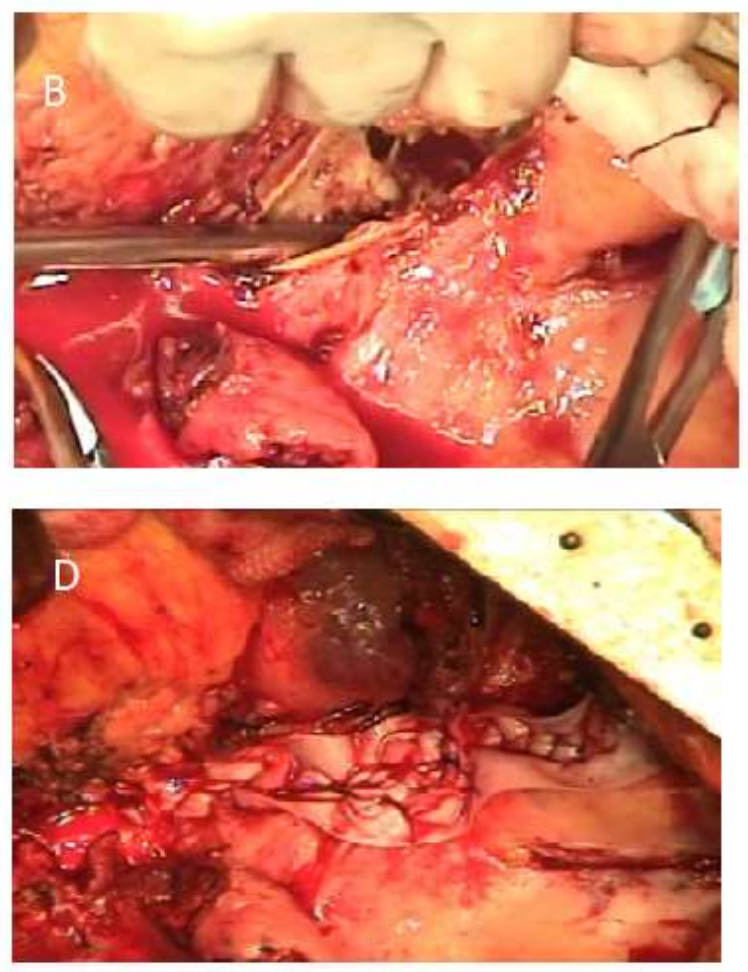

Figure 5. Operative findings (patient 8). A: The aneurysm of the thoracoabdominal aorta was markedly expanded. Severe adhesion around the aneurysm was observed. CA and SMA were exposed and taped. B: A vertical aortotomy was made. The defect of intima $(5 \times 2.5 \mathrm{~cm})$ was found at the anterior of the aorta. C: The bovine pericardial patch $(3 \times 7 \mathrm{~cm})$ angioplasty was performed with 3-0 Prolene continuous sutures using bovine pericardial strips with preserving intercostal arteries (Th10,11, 12). D: The aortotomy was closed using bovine pericardial strips. 

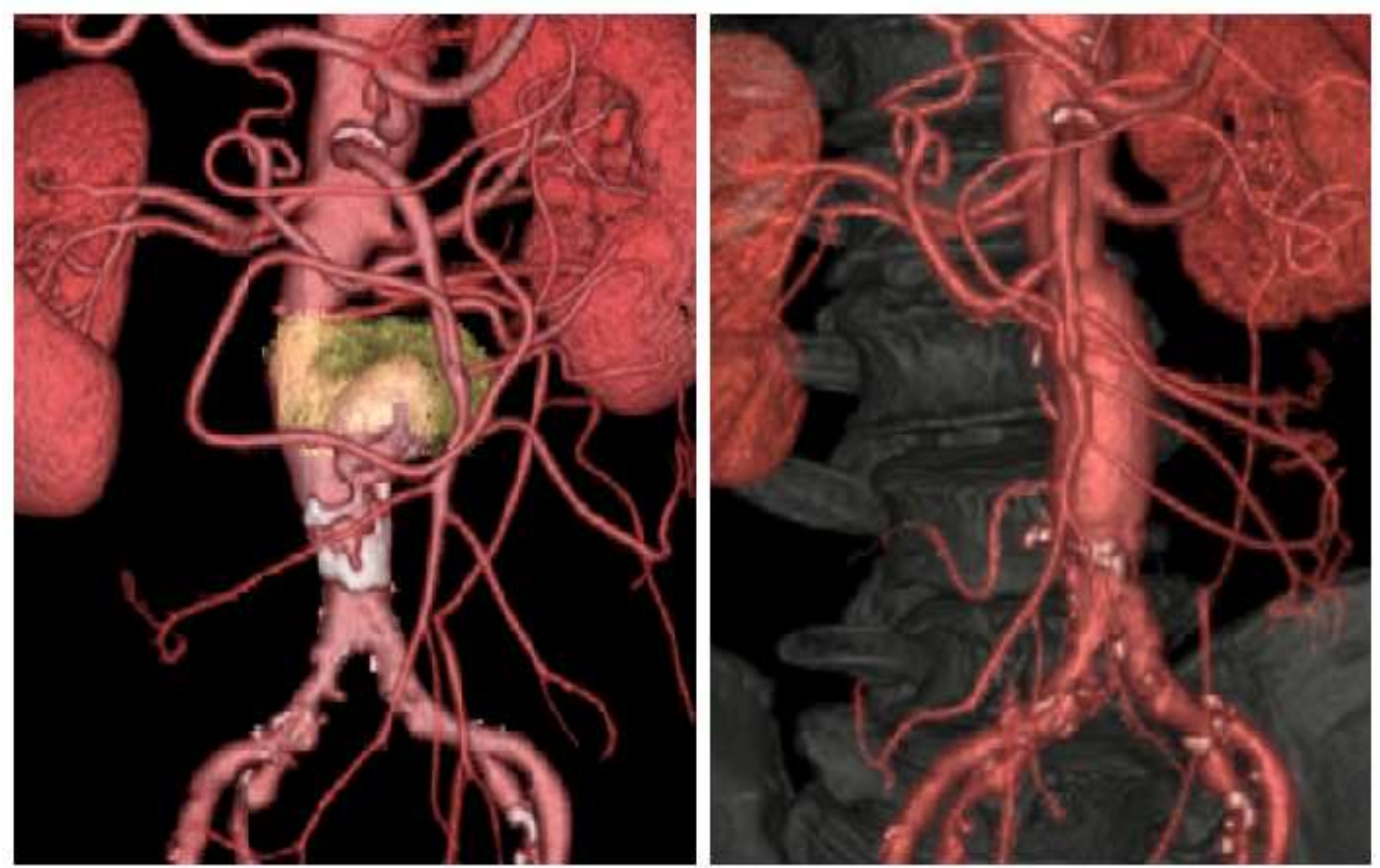

Figure 6: Preoperative and Postoperative CT angiography (patient 7).

In one patient (patient 5) had an aneurysm ruptured into colon preoperatively, a colostomy was performed simultaneously. Retroperitoneal spaces were implanted with greater omentum in six patients.

Written informed consent was achieved from all patients before the operation.

\section{Results}

There was no surgical/hospital death. The blood cultures demonstrated positive for $\alpha$-streptococcus in one patient (patient 6) and seven patients

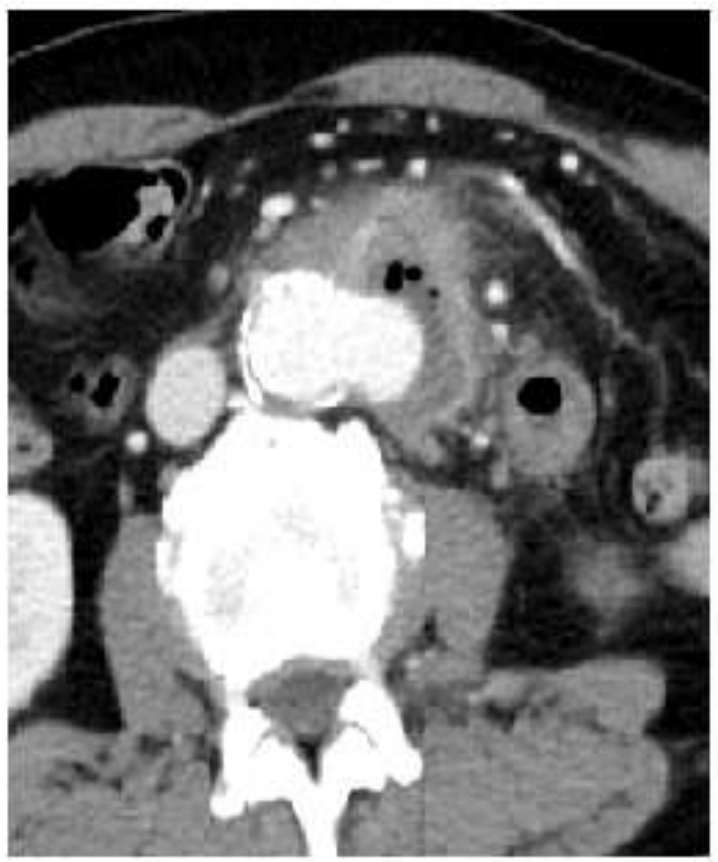

negative. The intraoperative abscess cultures showed positive for methicillin-resistant Staphylococcus aureus (MRSA) in one patient (patient 5) and seven patients negative. There was no surgical/hospital death. There were two late deaths at follow-up. A 74-year-old man (patient 6) who had an infrarenal abdominal aortic aneurysm with aortosigmoid colon fistula with melena had a BPPA with omentopexy and colostomy. The patient was re-admitted to the hospital with vomiting blood four months after surgery, and he underwent a total gastric resection due to hemorrhagic gastric ulcer, but the patch angioplasty site became a re-mass, ruptured and died (Figure 8).

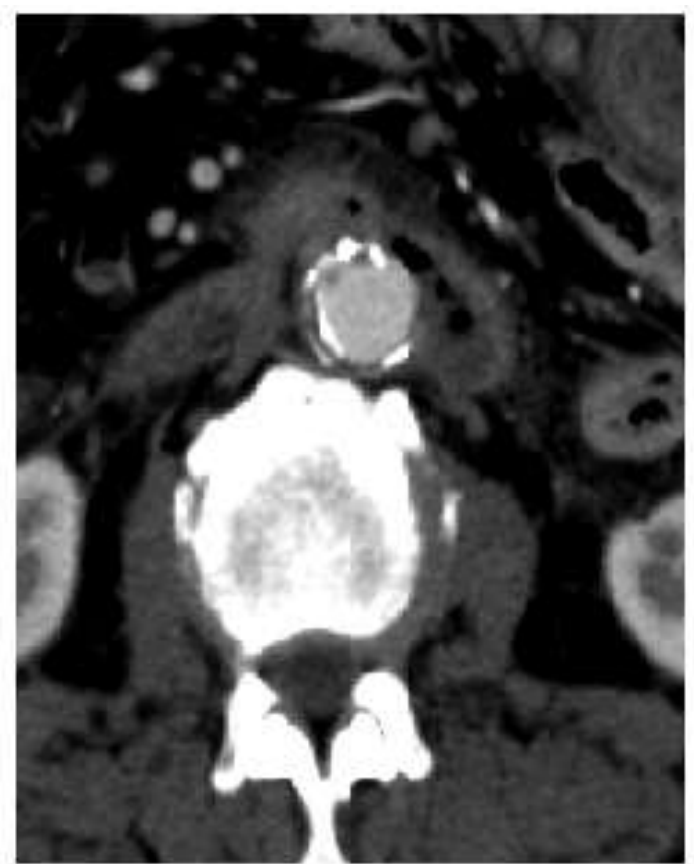


Another patient (patient 5) died at his home 12 months after surgery, and the cause of death was unknown (Figure 9).
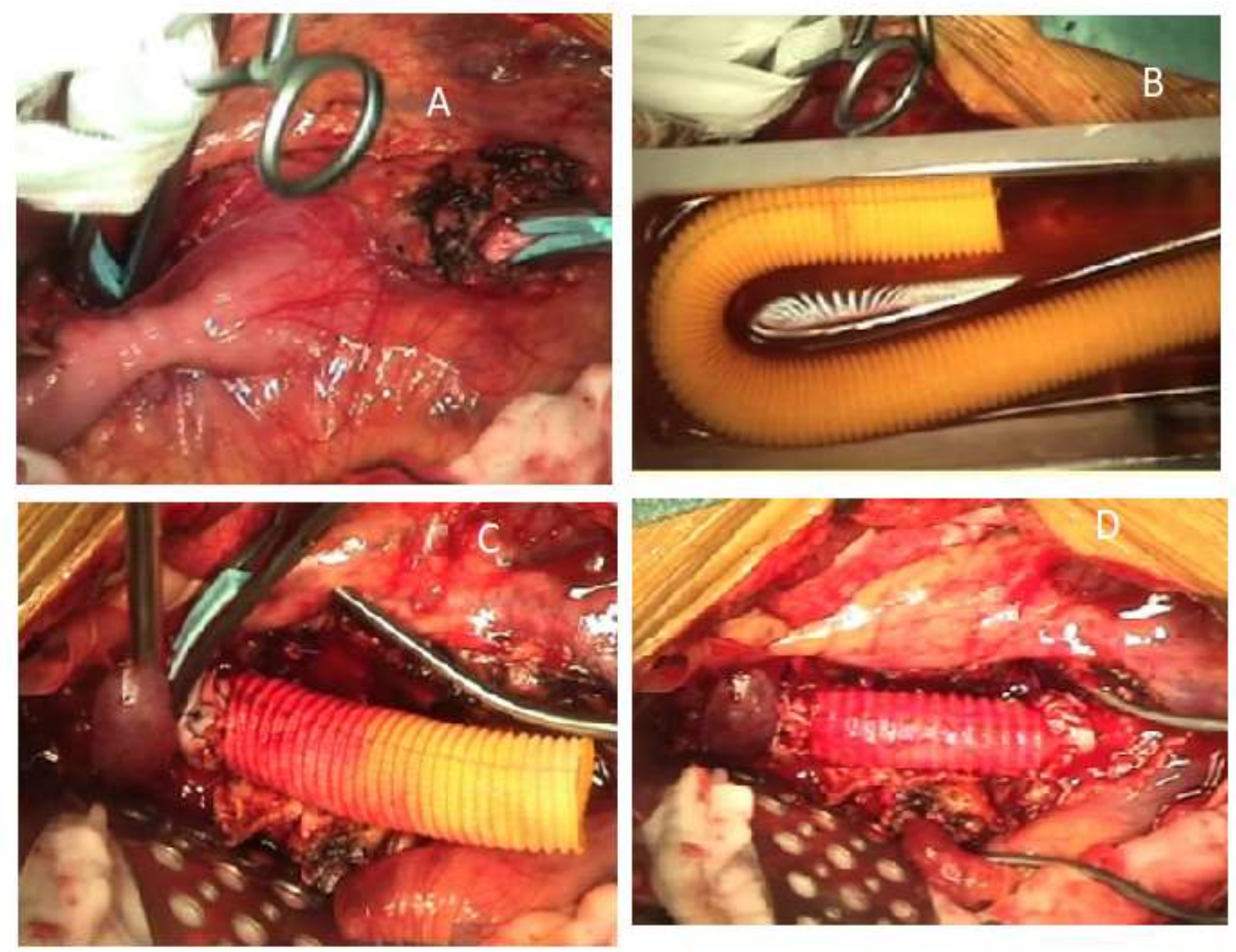

Figure 7. Operative findings (patient 7). A: The aneurysm of the infrarenal abdominal aorta was markedly expanded. Severe adhesion around the aneurysm was observed. The aorta was clamped. B: The graft was soaked with Rifampicin. C: The proximal anastomosis between the graft and the proximal aorta was performed. D: The graft replacement was completed.

Six patients remained alive with no evidence of recurrent aneurysm formation due to infection at a follow-up from 13 to 110 , mean 70.3 months (Figure 10).
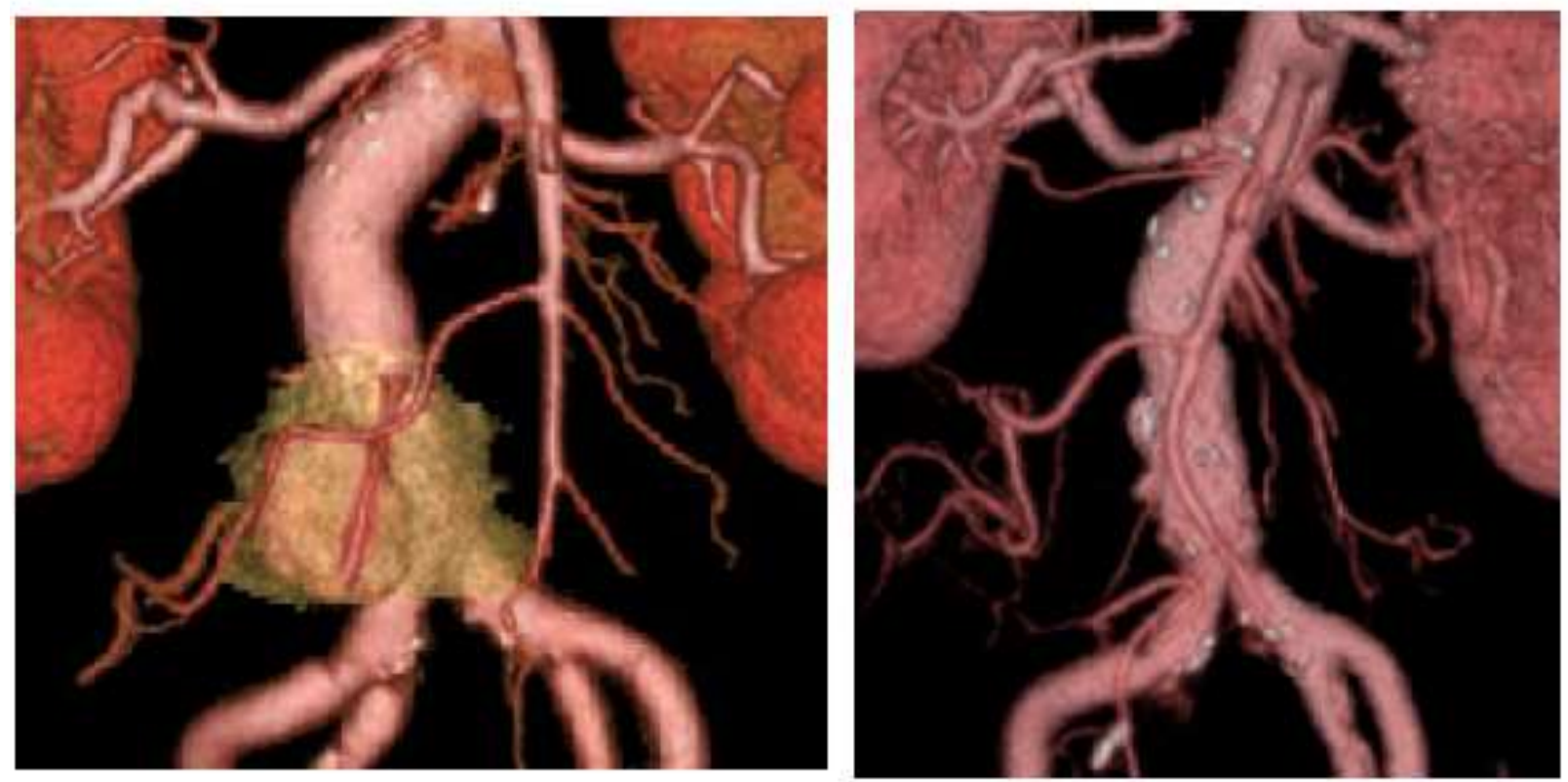

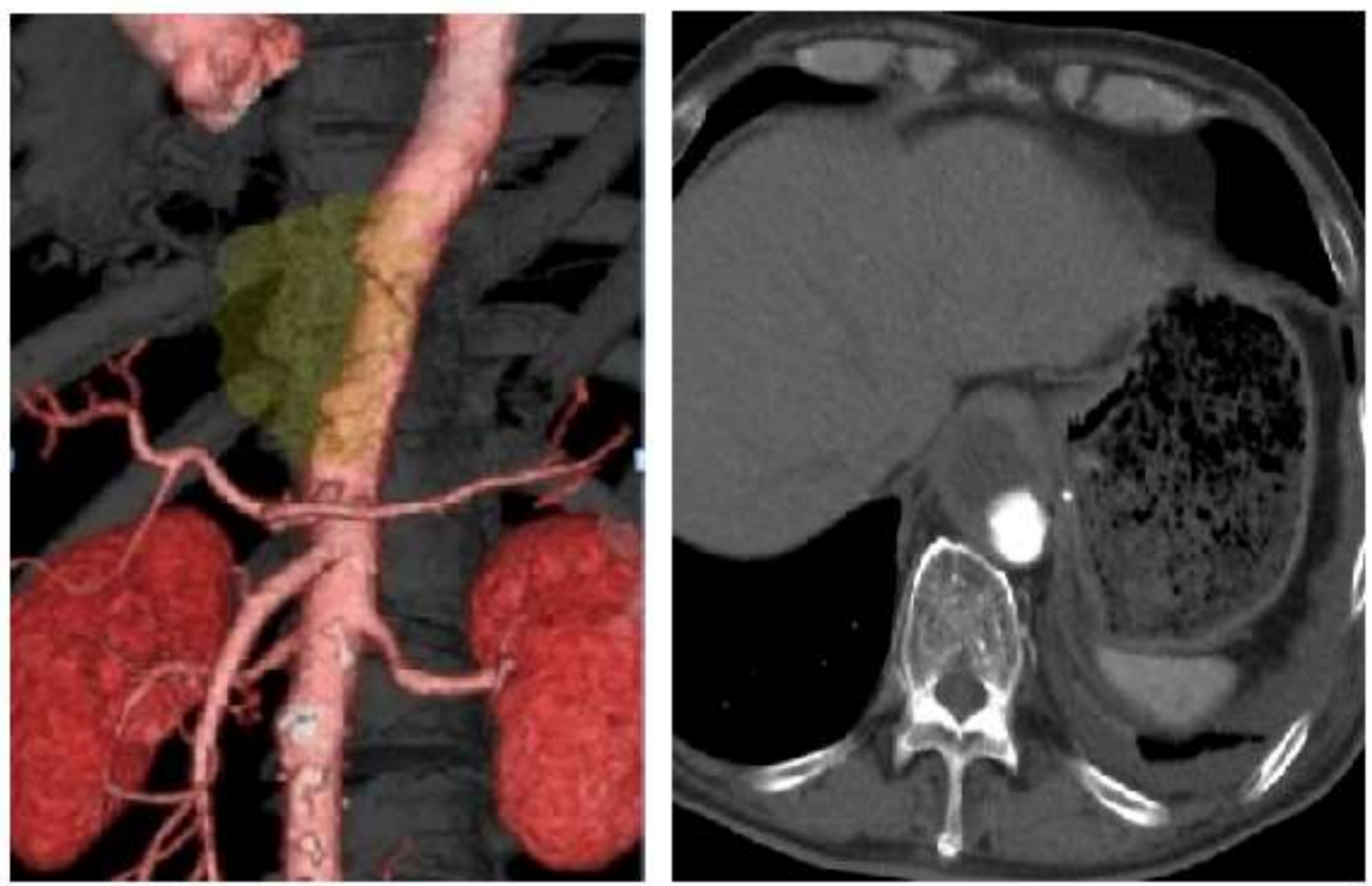

Figure 10. Postoperative thoracoabdominal CT angiography (12 months after surgery) (patient 8 ).

\section{Discussion}

IAA is a life-threatening condition with difficult treatment and poor survival. In addition to systemic antibiotic treatment, complete removal of the infected aorta, debridement of the surrounding tissue, and in situ aortic reconstruction is the standard procedure for treating IAA, but which graft material is best is a matter of debate.

A cryopreserved arterial allograft [10], rifampicin-soaked Dacron graft [9], equine [11] or bovine pericardial roll graft [12], superficial femoral vein [13], and great saphenous vein spiral graft [14] as surgical material have been reported.

Although use of an autologous arterial patch for IAA has been reported [7], to our knowledge, there have been no cases except for the case who we have previously published [8] that underwent reconstructive surgery using BPPA. BPPA for infected thoracoabdominal aortic aneurysm in our patients (patients 4 and 8 ) has been challenging. A search of the literature retrieved no publications that described the same procedure for infected thoracoabdominal aortic aneurysm.

Garcia et al. [4] present five cases of vascular reconstruction using BPP for the field of infection in immunosuppressive transplant patients and state that the use of autologous grafts in these patients is likely to significantly increase operative time and give another site to the risk of infection, however BPP is quickly accessible and useful.

McMillan et al. [6] used BPPs to repair infected fields of 51 arteriotomies in 48 consecutive patient undergoing removal of infected polytetrafluoroethylene grafts, and 50 of the 51 patches remained in place over a mean follow-up period of 2.1 years without evidence of recurrent infection, rupture, or revision. They concluded that BPP provides a durable option to saphenous vein for arterial reconstruction following removal of infected arterial grafts.
Bovine pericardium does not require long-term anticoagulation and has been associated with a lower risk of infection and thrombosis compared to synthetic materials. The patch material most proved durable in the arterial applications as a patch for carotid endarterectomy [15]. There are several case reports of BPP used for cardiac and pulmonary reconstruction in infected fields, and they have indicated good results and durability $[5,16]$. The definitive low rate of infection linked to BPPs has suggested that BPPs may be resistant to infection and therefore might be an suitable material to use in the presence of infection[6]. There was the following as positive characteristics of this bioprosthetic material: the soft-ness of the biological tissue, which permits simple surgical handling, the good coaptation to suture lines resulting in a hemostatic anastomosis, and the lower thrombogenicity of glutaraldehyde-treated collagen tissue $[17,18]$.

BPPA has low invasiveness because it minimizes the dissection range around the aneurysm, and handling of bovine pericardium is easy, which may shorten the operative time. In addition, bovine pericardium causes fewer cases of infection due to the antimicrobial effect of glutaraldehyde compared with those caused by a Dacron graft [19] which suggests that patch angioplasty using bovine pericardium is useful for treatment of saccular IAA that is hard to dissect. However, when the tissue is fragile and patch angioplasty is considered difficult, it is significant to remove the fragile tissue and infection focus immediately and accomplish in situ aortic replacement as in patient 7 . False aneurysm formation long after patch angioplasty of saccular aortic aneurysm with an artificial graft has been reported [20], suggesting the necessity of careful follow-up.

There were two late deaths in the present series. In these cases where the aneurysm is adhered to the sigmoid colon with melena as in patients 5 and 6 , reconstruction using bovine roll graft may be better than patch angioplasty because it seems to be more infectious $[11,12]$. 
Considering the characteristic feature of saccular form in IAA and to save the renal ischemic time, we performed a BPPA of the aneurysmal neck. We found that the renal ischemic time was acceptable with this procedure as in patient 1 and patient 2 . A standardized strategy to routinely apply renal hypothermia during the ischemic period of elective juxtarenal aortic aneurysm surgery may reduce postoperative renal failure [21]. Endovascular aortic repair (EVAR) is a less invasive alternative to traditional open repair of IAA. A major disadvantage is that the infected tissue, including the aneurysm itself, is not removed, which may cause persistent sepsis and infection of endoprosthesis. EVAR could be considered a temporizing alternative or a bridge to later elective open repair [2,22].

Because long-term results of this procedure are still unknown, long-term antibiotic treatment was given postoperatively. Recently, PET/CT scan was applied in the diagnosis of infected aortic aneurysm. Reeps et al. [23] reported finding of increased aortic FDG uptake on FDG-PET/CT scan was correlated with inflammation, histopathologic characteristics of aneurysm wall instability, and clinical symptoms. Moreover, PET/CT made an important contribution for monitoring response to antibiotic treatment. The optimal duration of antibiotic cover is a matter for expert opinion, although prospective use of PET/CT to determine inflammatory activity could prove valuable to guide such recommendations [24].

\section{Conclusion}

Surgical outcome for IAA was satisfactory. BPPA could be one of the surgical options, especially in patients with severe adhesion around the aneurysm. The long-term follow-up is warranted to further validate the advantage/disadvantage.

\section{References}

1. Claudio S. Cinà, Goffredo O. Arena, an Ali O. Fiture, a Catherine M. Clase. (2001). Ruptured mycotic thoracoabdominal aortic aneurysms: A report of three cases and a systematic review. J Vasc Surg; 33: 861-867.

2. Ting ACW, Cheng SWK, Ho P, et al. (2005). Surgical treatment of infected aneurysms and pseudoaneurysms of the thoracic and abdominal aorta. Am J Surg; 189:150-154.

3. Harada H, Tong X, Kuriyama N, Kobayashi D, Kimura F, et al. (2019) Reconstruction with a Bovine Pericardial Patch of Infected Juxtarenal Aortic Aneurysm. J Clin Case Stu 4(1): dx.doi.org/10.16966/2471-4925.184

4. Garcia Aroa S, Spaggiari M, Jeon H, et al. (2017). The use of bovine pericardial patch for vascular reconstruction in infected fields for transplant recipients. J Vasc Surg Cases and Innovative Techniques; 3: 47-49.

5. Shinn SH, Sung K, Park PW, Lee YT, Kim WS, et al. (2009). Results of annular reconstruction with a pericardial patch in active infective endocarditis. J Heart Valve Dis; 18: 315-320.

6. McMillan WD, Leville CD, Hile CN. (2012) Bovine pericardial patch repair in infected fields. J Vasc Surg; 55:1712-1715. doi: 10.1016/j.jvs.2011.11.139.

7. Lee SK, Lee KB, Kim DI, Kim YW (2007). Autologous Arterial Patch Closure of a Mycotic, Inter-renal Aortic Aneurysm. EJVES Extra; 14: 25-27.

8. Harada H, Tong X, Kuriyama N, Kimura F. (2018). Bovine Pericardial Patch Plasty for Ruptured Infected Abdominal Aortic Aneurysm in the Aged. Japanese J Vasc Surg 27: 277-280.

9. Kim YW (2010). Infected Aneurysm: Current Management. Ann
Vasc Dis. 3: 7-15.

10. Brown KE, Heyer K, Rodriguez H, Eskandari MK, Pearce WH, et al. (2009). Arterial reconstruction with cryopreserved human allografts in the setting of infection: A single-center experience with midterm follow-up. J Vasc Surg; 49: 660-666.

11. Yamamoto H, Yamamoto F, Ishibashi K, Motokawa M (2009). In situ replacement with equine pericardial roll grafts for ruptured infected aneurysms of the abdominal aorta. J Vasc Surg; 49: 10411045.

12. Czerny M, von Allmen R, Opfermann P, Sodeck G, Dick F, et al. (2011) Self-made pericardial tube graft: a new surgical concept for treatment of graft infections after thoracic and abdominal aortic procedures. Ann Thorac Surg; 92: 1657-1662.

13. Ohki S, Hirai H, Yasuhara K, Hatori K, Miki T, et al. (2016) Aortoiliac Artery Reconstruction Using Bilateral Reversed Superficial Femoral Veins for an Infected Abdominal Aortic Aneurysm. Ann Vasc Dis; 9: 70-72.

14. Aerts PD, van Zitteren M, Van Kasteren ME, Buiting AG, Heyligers JM, et al. (2013) Report of two in situ reconstructions with a saphenous spiral vein graft of Coxiella burnetii-infected aneurysms of the abdominal aorta. J Vasc Surg; 57: 234-237.

15. Ho K J, Nguyen LL, Menard MT, et al. (2012). Intermediate-term outcome of carotid endarterectomy with bovine pericardial patch closure compared with Dacron patch and primary closure. J Vasc Surg; 55: 708-714.

16. Us MH, Sungun M, Sanioglu S, Pocan S, Cebeci BS, et al. (2004). A retrospective comparison of bovine pericardium and polytetrafluoroethylene patch for closure of ventricular septal defects. J Int Med Res; 32: 218-221.

17. Puig LB, Casagrande IS, Kalil RA, Salles CA, Moreira MCV, Borem PM, et al. (1991) Early experience with crimped bovine pericardial conduit for arterial reconstruction. Eur J Cardiothorac Surg; 5: 273-279.

18. Salles CA, Puig LB, Casagrande IS, Vieira GL, Kalil RA,et al.(1998). Aortic reconstruction with crimped bovine pericardial conduits. J Heart Valve Dis; 7(3):305-312.

19. Kubota H, Endo H, Noma M, Ishii H, Tsuchiya H, et al. (2015). Xenopericardial roll graft replacement for infectious pseudoaneurysms and graft infections of the aorta. J Cardiothorac Surg; 10: 133.

20. Okita Y, Takamoto S, Ando M, Morota T, Yamaki F, et al. (1997). Long-term results of patch repair for saccular aneurysms of the transverse aortic arch. Eur J Cardiothorac Surg 11: 953-956.

21. Yeung KK, Jongkind V, Coveliers HME, Tangelder GJ, Wisselink W (2008). Routine Continuous Cold Perfusion of the Kidneys during Elective Juxtarenal Aortic Aneurysm Repair. Eur J Vasc Endovasc Surg; 35: 446-451.

22. Sörelius K, Mani K, Björck M, Sedivy P, Wahlgren CM, et al. (2014). Endovascular treatment of mycotic aortic aneurysms: a European multicenter study. Circulation 130: 2136-2142.

23. Reeps C, Essler M, Pelisek J, Seidl S, Eckstein HH. (2008). Increased 18F-fluorodeoxyglucose uptake in abdominal aortic aneurysms in positron emission/computed tomography is significantly associated with inflammation, aortic wall instability, and acute symptoms. J Vasc Surg; 48: 417-24

24. Fisk M, Peck LF, Miyagi K, et al. (2011) Mycotic aneurysms: a case report, clinical review and novel imaging strategy. $Q \mathrm{~J} \mathrm{Med}$; 105: 181-188. 


\section{To Submit Your Article Click Here: Submit Manuscript}

DOI: $10.31579 / 2690-8808 / 064$
Ready to submit your research? Choose Auctores and benefit from:

* fast, convenient online submission

* rigorous peer review by experienced research in your field

* rapid publication on acceptance

* authors retain copyrights

* unique DOI for all articles

* immediate, unrestricted online access

At Auctores, research is always in progress.

Learn more www.auctoresonline.org/journals/journal-of-clinical-casereports-and-studies 